\title{
Efficient Control of Active Transformers for Increasing the PV Hosting Capacity of LV Grids
}

Hashemi Toghroljerdi, Seyedmostafa; Østergaard, Jacob; Degner, Thomas; Brandl, Ron; Heckmann, Wolfram

\author{
Published in: \\ IEEE Transactions on Industrial Informatics
}

Link to article, DOI:

10.1109/TII.2016.2619065

Publication date:

2016

Document Version

Peer reviewed version

Link back to DTU Orbit

Citation (APA):

Hashemi Toghroljerdi, S., Østergaard, J., Degner, T., Brandl, R., \& Heckmann, W. (2016). Efficient Control of Active Transformers for Increasing the PV Hosting Capacity of LV Grids. IEEE Transactions on Industrial Informatics, 13(1), 270 - 277. https://doi.org/10.1109/TII.2016.2619065

\section{General rights}

Copyright and moral rights for the publications made accessible in the public portal are retained by the authors and/or other copyright owners and it is a condition of accessing publications that users recognise and abide by the legal requirements associated with these rights.

- Users may download and print one copy of any publication from the public portal for the purpose of private study or research.

- You may not further distribute the material or use it for any profit-making activity or commercial gain

- You may freely distribute the URL identifying the publication in the public portal 


\title{
Efficient Control of Active Transformers for Increasing the PV Hosting Capacity of LV Grids
}

\author{
Seyedmostafa Hashemi, Student Member, IEEE, Jacob Østergaard, Senior Member, IEEE, Thomas Degner, \\ Ron Brandl, and Wolfram Heckmann
}

\begin{abstract}
The increased penetration of grid-connected photovoltaic (PV) systems in low voltage (LV) grids creates concerns about overvoltage in these grids. The proposed methods to prevent overvoltage, such as reactive power absorption by $\mathrm{PV}$ inverters and active power management of customers, focus on decreasing the voltage rise along $L V$ feeders, and the potential of active medium voltage to low voltage (MV/LV) transformers for overvoltage prevention has not been thoroughly investigated. This paper presents the application of active MV/LV transformers for increasing the PV hosting capacity of LV grids. The potential interferences between the operation of active transformers and the reactive power absorption by $P V$ inverters are investigated, and a voltage droop control approach is proposed for the efficient control of these transformers during high PV generation periods. The proposed method can potentially increase the $\mathrm{PV}$ hosting capacity of the grid, while eliminating the need for a complex and centralized controller. The voltages of specific locations or the grid state estimations provide adequate data for adjustments of the droop parameters. The simulations and field test results associated with the implementation of the proposed method to a newly developed active LV grid with high PV penetration in Felsberg, Germany, confirm the efficiency of the proposed method.
\end{abstract}

Index Terms - low voltage grid, active transformer, high PV penetration, voltage control, reactive power management.

\section{INTRODUCTION}

$I_{\mathrm{po}}^{\mathrm{N}}$ recent years, the penetration of $\mathrm{PV}$ systems in electric power systems has increased. More than $38 \mathrm{GWp} \mathrm{PV}$ installations were reported in both 2013 and 2014, and at the end of 2014 the worldwide cumulative capacity had reached 177 GWp [1]. The majority of installed PVs are small-scale units, usually connected to LV distribution systems. According to EPIA, in 2012 rooftop PV took first place with

S. Hashemi and J. Østergaard are with the Center for Electric Power and Energy (CEE), Technical University of Denmark, Kgs. Lyngby, Denmark. (email: (shtog,joe)@elektro.dtu.dk).

T. Degner, R. Brandl, and W. Heckmann are with Fraunhofer IWES, Kassel, Germany. (email: (thomas.degner, ron.brandl, wolfram.heckmann) @iwes.fraunhofer.de).

The authors acknowledge the support of the work by the German Ministry for the Environment, Nature and Nuclear Safety and the Projektträger Jülich within the project "Aktives intelligentes Niederspannungsnetz" (FKZ 0325202), EAM GmbH \& Co.KG within the project "Regionale Energieversorgung 2020", EUDP within the project EnergyLab Nordhavn, and Energinet.dk under the Electrical Energy Research Program within the project PVNET.dk (ForskEL, 10698)

Copyright (c) 2009 IEEE. Personal use of this material is permitted. However, permission to use this material for any other purposes must be obtained from the IEEE by sending a request to pubs-permissions@ieee.org. around $12 \mathrm{GWp}$ in the net power generation capacities added into the 27 European countries' electricity grid [2]. Although the PV market is a policy-driven market, trends suggest that the rooftop PV penetration will continue to increase [2].

Due to the increase in decentralized PV installations, concerns regarding the effects of these new generation units on the power quality of LV grids have also increased. Reverse power flow, which can cause overvoltage in LV grids [3], [4], is associated with high PV penetration, and different methods are proposed for overcoming this challenge. Reactive power absorption by PV inverters is one of the solutions proposed to prevent overvoltage in the grid, and is usually applied to PV inverters using droop control methods [5]. Applying demand side management (DSM) [6] and energy storage application [4], [7] are other methods that can increase the load consumption during high PV generation periods and decrease the reverse power flow in the grid. The effectiveness of these methods depends on the grid characteristics, PV inverter technologies, and customers' behavior.

The majority of the proposed methods to prevent overvoltage focus on decreasing the voltage rise along LV feeders. The application of active MV/LV transformers is another of the methods that has been proposed recently, and it is applicable in almost all LV grids. The application of active $\mathrm{MV} / \mathrm{LV}$ transformers in LV grids with high PV penetration is investigated in [8], and it is concluded that these transformers can potentially solve the rise in voltage problem in high PV penetration conditions. In [9], a probabilistic simulation environment is proposed and by comparing the overvoltage occurrence frequencies of a grid with and without applying active transformers, the effectiveness of applying these transformers is shown. Another recent study has assessed different voltage control methods in 40 real LV grids and concluded that the application of an active MV/LV transformer has the highest technical potential to increase the PV hosting capacity of those grids [10]. Voltage unbalance can also be mitigated using three-phase MV/LV transformers with three decoupled single-phase tap-changer [11]. The utilization of active $\mathrm{MV} / \mathrm{LV}$ transformers in LV grids with high PV penetration is still rare; however, there is an increasing tendency to use these transformers to facilitate high PV integration in LV grids [12]. These active transformers can be transformers with on-load tap-changers (OLTCs) or solidstate and full power-electronic-based transformers. The structures of these transformers are different; however, their control concepts for grid voltage control are similar. 
Although the application of active transformers is an effective solution for overvoltage prevention, efficient control of the active transformers is essential to increase their lifespan and provide efficient voltage control in the grid during high PV generation periods. The methods proposed for controlling the active transformers for overvoltage prevention in high PV penetration conditions are mainly based on getting real-time feedback from all or selected buses in the grid using communication infrastructures and sending voltage set points to the control units of active transformers [5], [13]-[15]. However, the initial investment and ongoing operational costs of the information and communication technology (ICT) infrastructures can increase the overall cost considerably and decrease the economic efficiency of applying active transformers [5]. On the other hand, the local fixed voltage set point method, which does not require the ICT infrastructures, cannot fully exploit the technical advantages of applying these transformers even if tuned properly. In addition, as new PV inverters have the capability of the reactive power absorption during high PV generation periods, coordination between the reactive power absorption by $\mathrm{PV}$ inverters and the active transformer operation is required to prevent undesired operation of the transformer.

In this paper, a voltage droop control method is presented for the efficient control of active MV/LV transformers in high PV penetration conditions. This method allows a wider range of voltage increase and can potentially increase the PV hosting capacity of the grid. By using measured data available at the transformer substation, the need for ICT infrastructures is eliminated, and the effect of reactive power absorption on the operation of the active transformer can be considered in the method. The method is applied to an active LV feeder, located in Felsberg, Germany, and the proposed method and the simple fixed voltage set point approach are compared using the measured data.

The structure of the paper is as follows. In the section II, the voltage rise problem in high PV penetration is discussed. The methods proposed for increasing the PV hosting capacity of the grid using active and reactive power management are presented in section III. Then, the effectiveness of applying active $\mathrm{MV} / \mathrm{LV}$ transformers for overvoltage prevention and the proposed droop control method for efficient control of the transformer are discussed in section IV. Finally, simulations and field test results are discussed in section $\mathrm{V}$, and the paper conclusion is presented in section VI.

\section{Voltage InCREASE CAUSED By PV Systems}

To have an acceptable voltage profile at the customer point of common coupling (PCC), the maximum and minimum voltages of the customers have to be kept in the allowed band determined by the standards. Active power feed-in by PV systems can increase the PCC voltage to an unacceptable level. To examine a worst-case scenario concerning overvoltage, let us suppose that all PVs are collected at the end of the feeder, as shown in Fig. 1. The net feed-in current to the grid from the PV PCC can be calculated by:

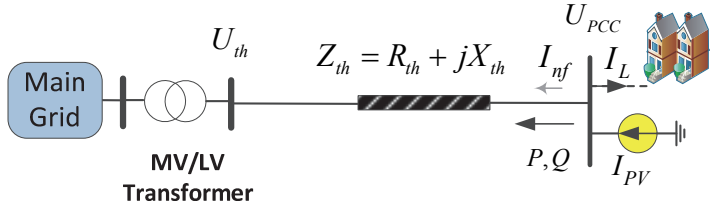

Fig. 1. A worst-case scenario concerning overvoltage, with all PVs collected at the end of feeder.

$$
\underline{I}_{n f}=\underline{I}_{P V}-\underline{I}_{L}=\left(\frac{\underline{S}_{n f}}{\underline{U}_{P C C}}\right)^{*} \simeq\left(\frac{P-j Q}{U_{t h}}\right)
$$

where $\underline{S} n f$ is the net apparent power injected into the grid, $\underline{U}_{t h}$ is the voltage at the $\mathrm{LV}$ side of MV/LV transformer, $\underline{U}_{P C C}$ is the voltage at the PV point of connection, $\underline{I}_{P V}$ is the PV feed-in current, and $I_{L}$ is the load consumption. The voltage at PCC can be calculated as:

$$
\begin{aligned}
\underline{U}_{P C C} & =U_{t h}+\underline{Z}_{t h} \underline{I}_{n f} \simeq U_{t h}+\left(R_{t h}+j X_{t h}\right)\left(\frac{P-j Q}{U_{t h}}\right) \\
& =U_{r}+j U_{i}
\end{aligned}
$$

where $\underline{Z}_{t h}$ is the thevenin impedance from the LV feeder of $\mathrm{MV} / \mathrm{LV}$ transformer to the PV bus, and $U_{r}$ and $U_{i}$ are the real and imaginary parts of the $\underline{U}_{P C C}$, respectively. For most connection points in distribution systems, the $U_{r}^{2} \gg U_{i}^{2}$ [10]; therefore, the approximate voltage magnitude at PCC can be simplified as follows:

$$
U_{P C C} \approx U_{t h}+\frac{P \times R_{t h}+Q \times X_{t h}}{U_{t h}}
$$

The voltage increase at PCC can be calculated as:

$$
\left(\Delta U \times U_{t h}\right) \approx\left(P \times R_{t h}+Q \times X_{t h}\right)
$$

According to the standards applied to LV grids, the voltage at the connection point has to be limited to a specific amount. Suppose that the maximum voltage increase is limited to $\Delta U_{\max }$; therefore, the maximum active power that can be injected into the grid without overvoltage is as follows:

$$
P_{\text {max }}=\left(\frac{\Delta U_{\text {max }} \times U_{t h}-Q \times X_{t h}}{R_{t h}}\right)
$$

If the active power increases to more than $P_{\max }$ defined in (5), the PCC voltage exceeds the allowed boundary. To illustrate further, the output power of a PV panel with a capacity of $10 \mathrm{kWp}$, located at the Technical University of Denmark, and its PCC voltage are shown in Fig. 2. The PV is connected to a weak grid, and a voltage dependent active power curtailment strategy is applied to the PV inverter to prevent overvoltage. As can be seen, due to a switching action in the MV network, the active power output is reduced by around $17 \%$ at around 11:00. In addition, during the time when the PV generation usually peaks, the PV output is curtailed at around $5.5 \mathrm{~kW}$.

\section{INCREASING THE PV Hosting CAPACITY USING THE Active AND REACtive Power MANAGEMENT}

According to (5), three main factors determine the $P_{\max }: \Delta U_{\max }, Q \times X_{t h}$, and $R_{t h}$. To decrease the $R_{t h}$, the lines 


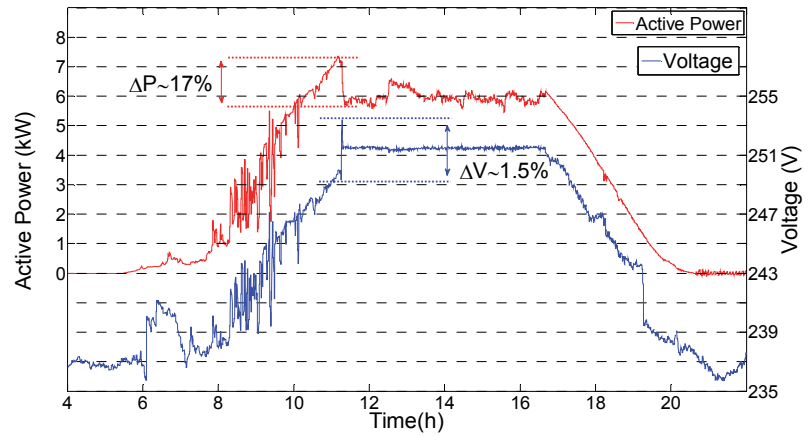

Fig. 2. Output power of a PV panel and its PCC voltage.

have to be replaced by stronger lines or new lines have to be constructed to reinforce the grid. Although the grid reinforcement is an effective solution, the associated cost is usually high [16]. The reactive power absorption by PV inverters and active power management are other methods that are described in the following.

\section{A. Active power management}

The active power management can be performed using three main approaches: active power curtailment, demand side management (DSM), and application of electrical energy storage systems (EESS). By controlling the maximum power point tracker (MPPT) of PV systems, the output power can be curtailed at a specific level [17]. The active power curtailment can be applied using static and dynamic methods. Dynamic curtailment methods have higher efficiency and less active power loss and can act based on the grid voltage using voltage dependent droops as well as centralized controllers [18]. DSM is another method proposed to increase the PV hosting capacity of LV grids. By transferring the peak-load consumption periods to the high PV generation periods, the voltage rise problem during high PV generation periods can be solved. As DSM depends to a great extent on customers' consumption patterns, it cannot be considered as a reliable solution for the grid voltage control [19]; however, a combination of DSM with active power curtailment can decrease the energy loss caused by curtailment [4].

In recent years, EESS have been proposed as a solution to mitigate the overvoltage in the grid. To this aim, the output power of PV can be limited to a specific amount by storing the excess energy, and this stored energy can be used when load consumption or the price of electricity is high. Although battery technologies have developed in recent years, the main concern about the application of EESS is still the initial investment in the system. In addition, advanced static or dynamic methods are needed to control these units as efficiently as possible, and it may increase the complexity and the initial investment [20], [21].

\section{$B$. Reactive power management by $P V$ inverters}

In higher voltage power systems in which the $\mathrm{X} / \mathrm{R}$ ratio is relatively high, reactive power control is the main tool for the voltage control of the system. As this ratio is lower in LV grids, reactive power control is not as effective as higher voltage grids. However, it is still an efficient solution in certain grids. The reactive power control is usually applied to the inverter controllers using the droop control methods, namely the reactive power as a function of voltage in the PV connection point $(Q(U))$, and power factor $(\mathrm{PF})$ as a function of injected active power $(P F(P))$ [5]. In the $Q(U)$ method, the voltage at the $\mathrm{PV}$ connection point is considered as a reference for the droop control and the PV inverter absorbs the reactive power only when the terminal voltage is higher than a specific value. In the $P F(P)$ method, the reactive power is a function of the generated active power and the droop characteristics can be set so that during low PV generation hours, no reactive power is absorbed by the PV inverter. It is worth mentioning that the reactive power absorption by the $\mathrm{PV}$ inverter increases the power loss and congestion of distribution lines.

\section{Voltage Control Using Active MV/LV TRANSFORMERS}

The LV distribution systems were designed according to the load cases, not the local generation. As the number of LV networks is high, cost-effective solutions with longer life spans that also need less maintenance are required to prevent overvoltage. The majority of the proposed methods for overvoltage prevention focus on decreasing the voltage rise along LV feeders. According to (3), the PCC voltage also depends on the voltage on the LV side of MV/LV transformer. In many LV distribution grids, the voltage variations on the MV side cannot be mitigated, as the tap positions of MV/LV transformers are fixed. Although the voltage tolerance band is usually $\pm 10 \%$ [22], $\Delta U_{\text {max }}$ is usually limited to less than $5 \%$ to ensure acceptable voltage at the PCC. To illustrate further, a typical design consideration for distribution systems in Germany is depicted in Fig. 3 [23]. As can be seen, the maximum voltage increase in LV grids is limited to $3 \%$, which can potentially limit the maximum PV installation.

By utilizing active MV/LV transformers, the voltage of an LV grid can properly be controlled and the need for other voltage controllers is eliminated in many LV grids. In the case of applying voltage regulators and active transformer in an LV grid, the coordination between voltage regulators and active transformer is required and settings of voltage regulators have to be adjusted properly. It is worth mentioning that the active transformer is a grid voltage forming unit and it acts as the main voltage controller in the LV grid. Other voltage regulators in LV grids are grid following units and can change the voltage slightly compared to the active transformer.

As discussed before, efficient control of the active transformer is essential to provide efficient voltage control in the grid during high PV generation periods. A simple method for controlling active transformers is applying a fixed set point to the transformer controller. The method and its drawbacks are discussed in the following.

\section{A. Fixed voltage set point}

A simple method to control the tap changer is to keep the voltage at the LV side of the transformer constant based on a 


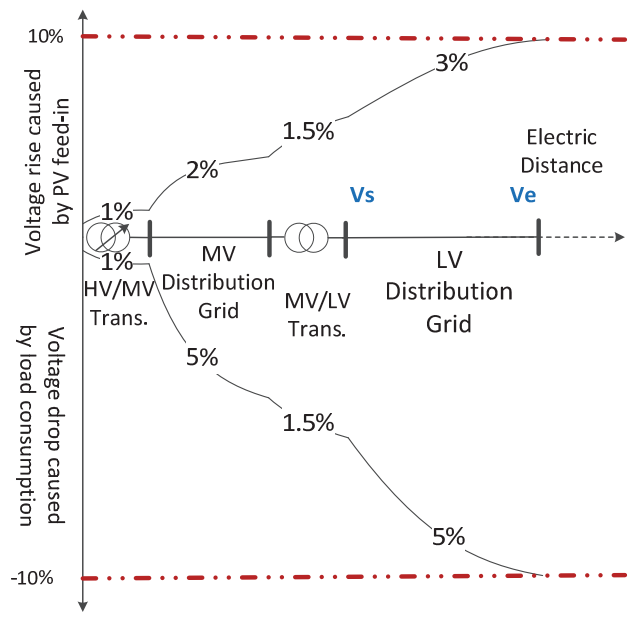

Fig. 3. A typical distribution system design concept.

predefined set point. In this condition, the voltages of MV and LV grids are decoupled; therefore, the voltage variations are limited to the controller deadband, as shown in Fig. 4. The deadband is applied to prevent the frequent operation of the voltage regulator and to increase its lifespan.

Although the fixed set point method is a simple and easyto-implement approach, the boundary of voltage variation in this method is limited. As can be seen from Fig. 4, there are boundaries for the maximum acceptable voltage increase, $\Delta V_{\text {Rise }}$, and the maximum acceptable voltage decrease, $\Delta V_{\text {Drop }}$. During high load consumption periods the grid voltage has to be kept higher than the minimum band; therefore the maximum voltage increase has to be limited to: $\Delta V_{\max }-\Delta V_{\text {Drop }}$-Deadband. $\Delta V_{\max }$ is voltage fluctuation boundary determined by the grid codes and standards. For instance, if the acceptable voltage decrease in LV grid is $8 \%$, and by considering a deadband of $4 \%$, the maximum voltage increase has to be limited to $8 \%$.

Another difficulty associated with the application of the fixed set point method is the miscoordination between the active transformer and the reactive power compensation by PV inverters. As mentioned previously, the reactive power absorption by PV inverters can decrease the voltage at the PV PCCs and increase the PV hosting capacity of the grid. As the $\mathrm{X} / \mathrm{R}$ ratio of cables of $\mathrm{LV}$ grids is relatively small, the main voltage drop caused by the reactive power absorption happens at the LV side of MV/LV transformer. This voltage drop may cause the undesired operation of OLTC and increase the voltage at the connection point. To illustrate further, suppose that the voltage at the primary of the transformer is fixed at $V_{l}$, the power factor of the $\mathrm{PV}$ inverters is $P F$, and the $\mathrm{X} / \mathrm{R}$ ratio of the transformer is $R a$. Using (3), the voltage at the terminal of the transformer can be estimated as:

$$
V_{2} \approx V_{1}+\frac{P \times R-\tan \left(\cos ^{-1}(P F)\right) \times P \times R(R a)}{V_{1}}
$$

For a typical $630 \mathrm{kVA}, 20 / 0.4 \mathrm{kV}$ distribution transformer with $R a=5.6$ and $u k \%=6$, the voltage drop at the terminal of

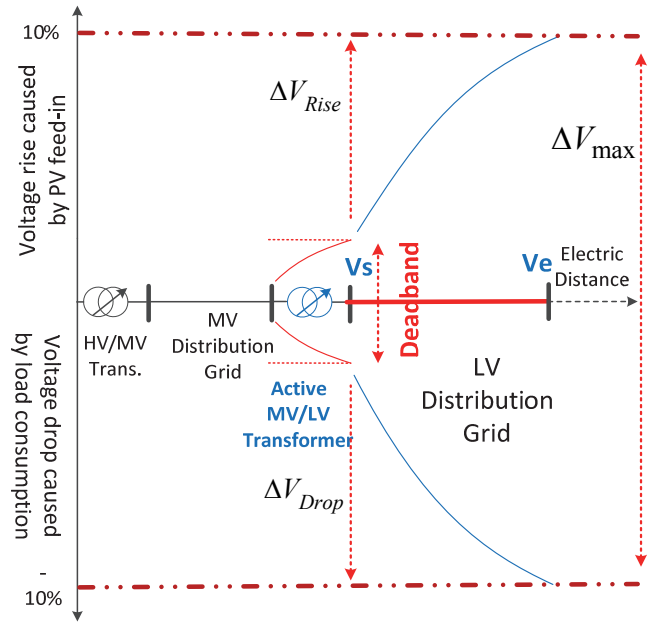

Fig. 4. Application of active MV/LV transformer for increasing the PV hosting capacity. A fixed set point is applied to the transformer.

transformer may exceed $1.5 \%$ in high PV penetration conditions. As the primary voltage of the transformer is variable, even a smaller voltage drop may cause the OLTC operation. In addition, the passing clouds that can cause active power fluctuations at the transformer secondary may cause the frequent operation of the OLTC.

\section{B. Voltage droop control method}

To increase the boundary of voltage fluctuation, the voltages of different buses in the grid can be measured. Based on these voltages, the voltage of the active transformer can be determined. However, these communication-based methods require high initial investment and operational costs. Because of the high investment and operational costs associated with ICT infrastructures, which affect the overall economic efficiency of applying active transformers, locally controlled approaches are preferred as long as they can control voltage properly. The proposed voltage droop control can potentially increase the voltage fluctuation boundary and provide the possibility of coordination between the transformer controller and PV inverters. Using this method, the voltage set points are lower during high PV generation periods and are higher during high load consumption, and it allows higher voltage rise and voltage drop along the LV feeder. As a result, the PV hosting capacity of the grid can potentially be increased and the voltage profiles of the customers can also be improved. The schematic of the droop is shown in Fig. 5. The droop characteristics can be summarized as follows:

$$
\begin{aligned}
& V_{s}=V_{1} \quad \text { if } \quad P_{m}<P_{1} \\
& V_{s}=V_{1}+\left(\frac{V_{2}-V_{1}}{P_{2}-P_{1}}\right)\left(P_{m}-P_{1}\right) \quad \text { if } P_{1}<P_{m}<P_{2} \\
& \left\{V_{s}=V_{2} \quad \text { if } P_{2}<P_{m}<P_{3}\right. \\
& {\left[\begin{array}{ll}
V_{s}=V_{2}+\left(\frac{V_{3}-V_{2}}{P_{4}-P_{3}}\right)\left(P_{m}-P_{3}\right) & \text { if } P_{3}<P_{m}<P_{4} \\
V_{s}=V_{3} & \text { if } \quad P_{m}>P_{4}
\end{array}\right.}
\end{aligned}
$$

where $V_{s}$ is the tap changer set point, $P_{m}$ is the active 


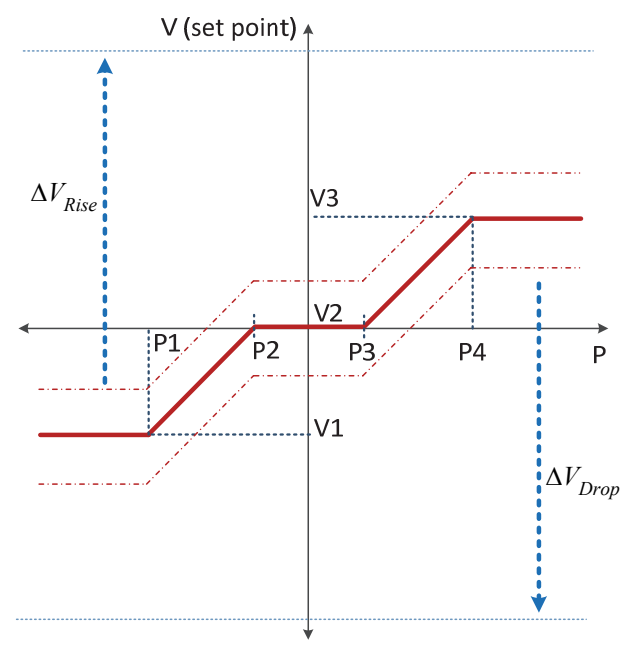

Fig. 5. The schematic of the droop control method.

power measured at the transformer LV terminal, and $V_{1}, V_{2}$, $V_{3}, P_{1}, P_{2}, P_{3}$, and $P_{4}$ are the predefined droop settings.

The droop voltage settings can be determined according to the maximum PV penetration and the maximum load consumption in the grid. Grid state estimations [24] or having voltage measurements from one of the PV locations with the highest voltage increase and one of the loads with the highest voltage decrease can provide adequate information to adjust the settings of the droop. The historic data provided by smart meters [25] in these specific locations can also provide proper information for adjustments of the droop settings, and realtime feedbacks and having a centralized controller are not necessary. Considering the prescribed deadband, the tap changer operation can be summarized as follows:

tap $=\left\{\begin{array}{lr}\text { if } V_{m}<\left(V_{s}-\frac{V_{\text {deadband }}}{2}\right) \\ \text { No action } \text { if }\left(V_{s}-\frac{V_{\text {deadband }}}{2}\right)<V_{m}<\left(V_{s}+\frac{V_{\text {deadband }}}{2}\right) \\ \text { tap }-1 & \text { if } V_{m}>\left(V_{s}+\frac{V_{\text {deadband }}}{2}\right)\end{array}\right.$

where $V_{m}$ is the measured voltage at the LV side of the transformer. If the fixed voltage set point approach is applied, $V_{s}$ is a fixed voltage. It is worth mentioning that when clouds pass by PV fields, both active power and voltage decrease; therefore, the voltage set point and the operating boundary of the active transformer also decrease and prevent the frequent operation of the transformer.

By applying the proposed method, the voltage of an LV grid can properly be controlled and the need for applying other voltage controllers is eliminated in many LV grids. It should be considered that the active transformer is a grid voltage forming unit and it acts as the main voltage controller in the LV grid. Other voltage regulators in the LV grid are grid following units and can change the voltage slightly compared to the active transformer; therefore, applying voltage regulators as well as reactive power absorption by PV

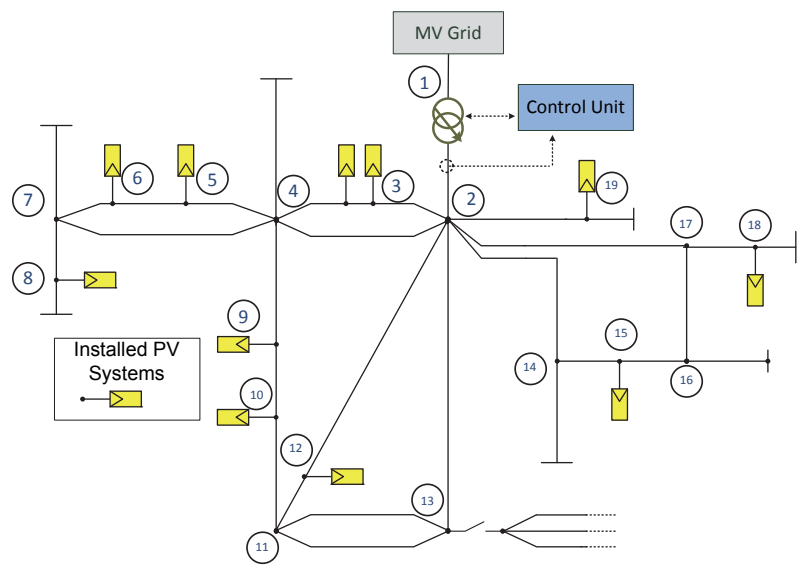

Fig. 6. The LV grid with MV/LV transformer equipped by OLTC

inverters is not required in many cases. In the case of applying voltage regulators and active transformer in an LV grid, the droop settings have to be adjusted properly.

As discussed before, reactive power absorption by $\mathrm{PV}$ inverters may cause undesired operations of active transformers that are controlled by the fixed set point approach. The proper adjustments of the proposed droop settings eliminate these undesired operations. It is because by increasing the PV generation, the reactive power absorbed by PV inverters increases; however, the operating voltage of the active transformer is also decreased according to the droop applied to the transformer. Therefore, the undesired operation of the transformer can be eliminated by proper adjustment of $P_{1}, P_{2}, V_{1}$ and $V_{2}$.

\section{Simulations And Field Test Results}

\section{A. Simulation Results}

A three-phase LV grid of Felsberg, Germany is selected for the simulations and field tests. The line-diagram of the test system is depicted in Fig. 6. A newly developed $630 \mathrm{kVA}$ $20 / 0.4 \mathrm{kV}$ transformer with controllable OLTC $( \pm 3 \times 2 \%)$ is located in this LV grid and around $250 \mathrm{kWp} \mathrm{PV} \mathrm{systems} \mathrm{with}$ the capability of reactive power absorption have been installed in the grid. The special design of the tap changer guarantees a maintenance-free operation up to 700,000 switching operations. Considering the life span of the transformers and by applying an efficient control system, the tap-changer operation is maintenance-free during its lifetime. Detailed information regarding the grid and the OLTC can be found in [23]. Matlab is used to model the selected LV grid.

For secure operation of LV systems, the grid voltage has to be kept in the allowed band and the power ratings of grid components, such as cables and $\mathrm{MV} / \mathrm{LV}$ transformer, also must not exceed the allowed ratings. As the nominal capacity of the transformer is $630 \mathrm{kVA}$ and the system is examined in no-load condition, the maximum achievable PV hosting capacity is considered as $630 \mathrm{~kW}$. For the simulations, it is supposed that the PV inverters are oversized, and the effects of reactive power absorption on the overloading of the grid components are considered. 


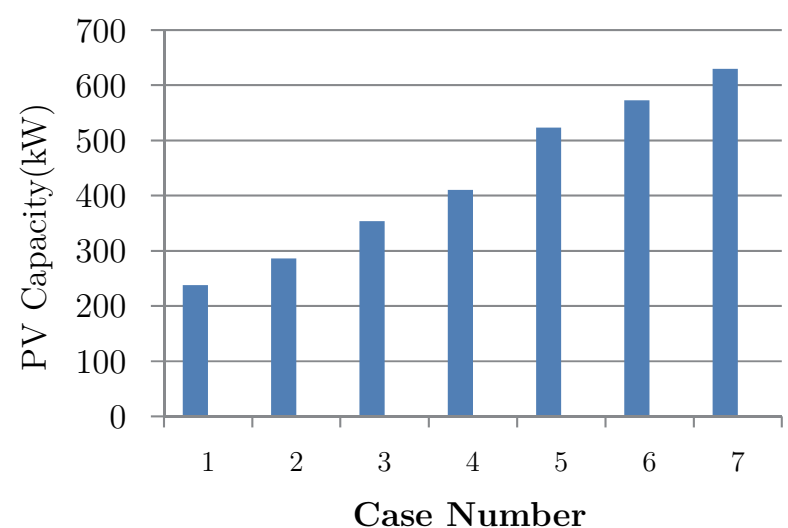

Fig. 7. The PV hosting capacities of the grid in different simulation cases; 1) current installed PV, 2): maximum PV hosting capacity without overvoltage prevention methods, 3): applying $\mathrm{PF}=0.95,4)$ : applying $\mathrm{PF}=0.9,5$ ): applying fixed set point and $\Delta U=8.5 \%$ with $\mathrm{PF}=1,6$ ): applying fixed set point and $\Delta U=8.5 \%$ with $\mathrm{PF}=0.9,7$ ): applying the proposed droop method and $\Delta U=10.1 \%$ with $\mathrm{PF}=1$.

The PV hosting capacities of the grid in different simulation cases are shown in Fig. 7. The current PV installation is around $38 \%$ of the maximum achievable PV hosting capacity and this penetration can be increased up to around $45 \%$, considering a maximum of $3 \%$ voltage increase in the grid. The PV penetration can be increased to around $56 \%$ and $65 \%$ if all PVs absorb reactive power with a power factor of 0.95 and 0.9 , respectively. Without other ancillary services, the PV installation has to be limited to $65 \%$.

By utilizing an active MV/LV transformer, the PV hosting capacity can increase considerably. By applying a fixed voltage set point with a deadband of $\pm 1.5 \%$ and without reactive power absorption by $\mathrm{PV}$ inverters, the PV hosting capacity can be increased from $45 \%$ to around $87 \%$. The reactive power absorption by all $\mathrm{PV}$ systems can increase the PV hosting capacity to $91 \%$. In this condition, the PV hosting capacity is limited by the maximum permissible apparent power of the transformer. To increase the PV hosting capacity in this condition, an optimized reactive power strategy is required. To this aim, the reactive power has to be absorbed by the PV systems that are located at the points with the highest sensitivities to the reactive power, or the voltage dependent reactive power absorption methods with an optimized droop characteristics, such as $\mathrm{Q}(\mathrm{U})$, are applied to the PV inverters.

By applying the voltage dependent droop, the PV hosting capacity can be increased to $100 \%$, without the need for reactive power absorption by PV inverters. In this condition, the droop has to be set so that a maximum $10.1 \%$ voltage increase in the grid is allowed, i.e. $\Delta V_{\text {Rise }}=10.1 \%$. As the reactive power increases the loading of the grid components, it can decrease the capacity for active power injection by PVs; therefore, the combination of reactive power absorption and voltage droop control of OLTC does not increase the PV hosting capacity of the grid when a droop is applied to the transformer.

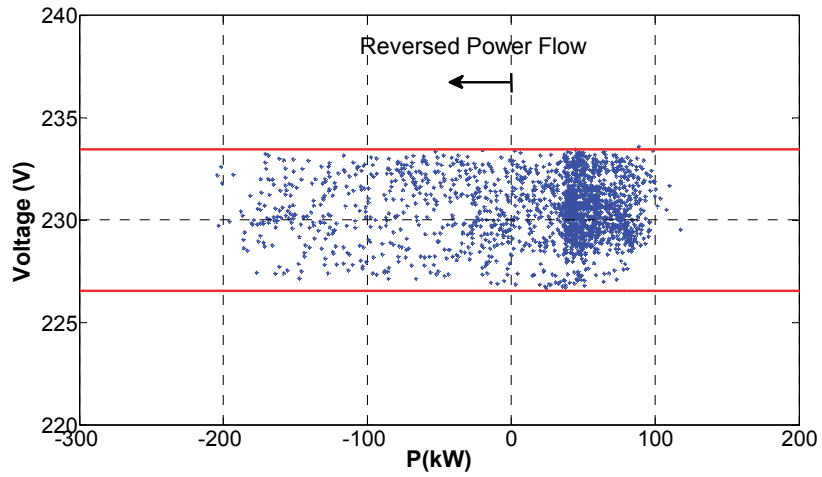

Fig. 8. Voltages of the MV/LV transformer with fixed set point approach.

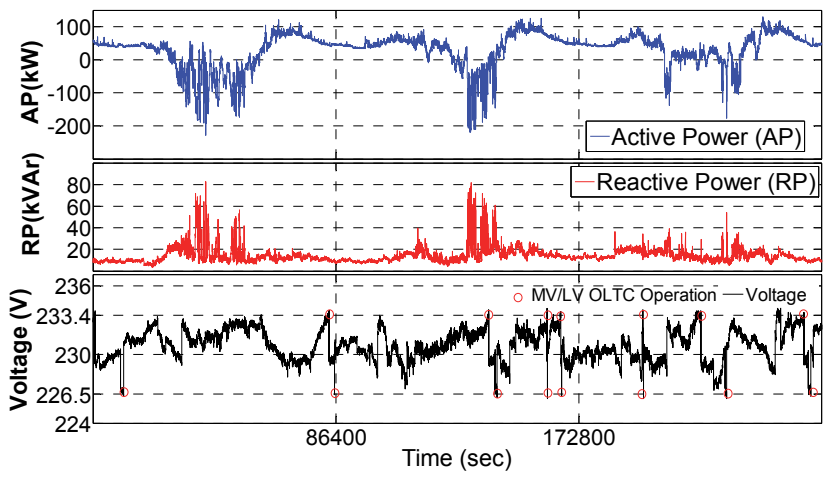

Fig. 9. The active power, reactive power, and the LV side voltage of the transformer during three successive days with fixed set point control.

\section{B. Field Test Results}

The fixed set point method was applied on the transformer with OLTC from August 21, 2013 to September 3, 2013. The 10-minute average voltage of the transformer LV side during the period is shown in Fig. 8. As can be seen, the voltage was in the boundary of $230 \pm 1.5 \%$. According to these settings, the allowed voltage rise and voltage drop in the grid were $8.5 \%$. The second-based active power, reactive power, and the LV side voltage of the transformer during three successive days are shown in Fig. 9. The negative active power values represent the reverse power flow into the MV distribution system. The switching actions of the OLTC are also shown in the figure. It is worth mentioning that other voltage steps were due to switching actions in the MV network.

The proposed droop method was applied on the previous LV grid from September 4, 2013 to October 18, 2013. The 10minute average voltages of the transformer LV side are shown in Fig. 10. As can be seen, the voltage followed the predefined characteristics. Using the proposed method, the allowed voltage rise and voltage drop are increased to $10 \%$ and they can be increased by more if the PV penetration or load consumption is increased. The second-based active power, reactive power, and the LV side voltage of the transformer during three successive days are shown in Fig. 11. The switching actions of the OLTC are also shown in the figure. As can be seen, during the periods with high PV generation the OLTC operated at a lower voltage compared to the periods with high load consumption. The normalized occurrence frequency of different voltages measured at the PCC of PV 


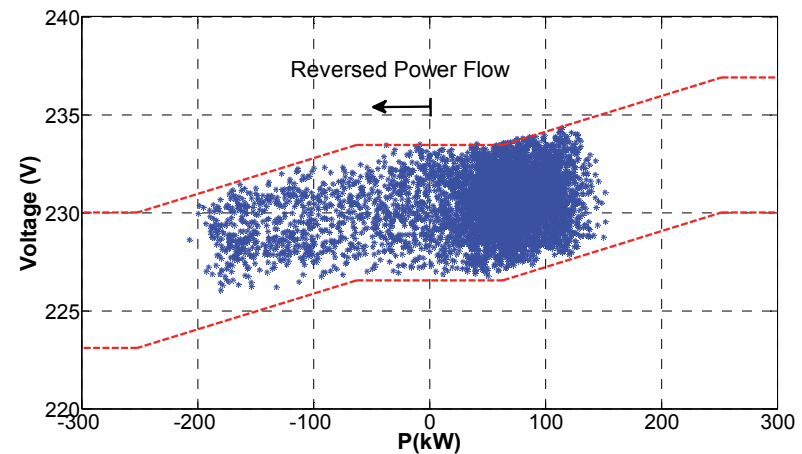

Fig. 10. Voltages of the LV side of the MV/LV transformer with the proposed droop method.

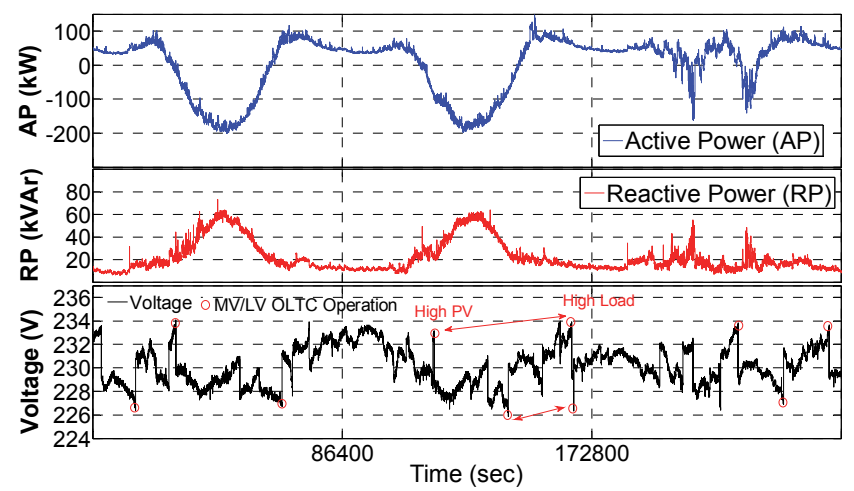

Fig. 11. The active power, reactive power, and the LV side voltage of the transformer during three successive days with droop control approach.

located at bus 6 for the fixed voltage set point and proposed methods are also shown in Fig. 12. As can be seen, using the proposed method, the maximum voltage rise in the grid caused by PVs was around $1 \%$ lower than the fixed voltage set point method. This confirms that more PVs can be installed in the grid in this condition.

The number of switching actions per day is shown in Fig. 13. Based on the measurements, the average switching of the OLTC with a deadband of $\pm 1.5 \%$ and the fixed set point of $230 \mathrm{~V}$ was 6.77 switching actions per day. Increasing the deadband to $\pm 2 \%$ decreased the allowed voltage drop and voltage rise to $8 \%$; however, the average number of switching actions was decreased to 4.35 switching actions per day. The average switching of the OLTC with a deadband of $\pm 1.5 \%$ and the droop method was 5.1 switching actions per day. The results confirm that the utilized tap-changer can be considered as maintenance-free during its lifespan.

It is worth mentioning that a DSM strategy is applied in the mentioned LV feeder in Felsberg, Hesse, Germany. Based on this strategy, the thermal storage units such as freezers, refrigerators and off-peak heating systems are directly controlled and other household loads are controlled indirectly using a bonus tariff incentive system [8]. A part of the results associated with the average daily load consumption without DSM in August 2012 and with DSM in the same month in 2013 are depicted in Fig. 14. The results confirmed that the DSM can shape the load consumption and improve the PV hosting capacity of the network, decrease the peak-load

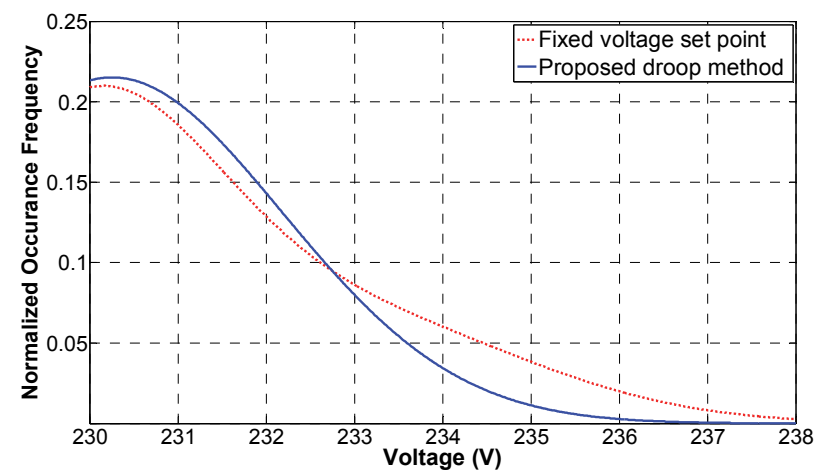

Fig. 12. The normalized occurrence frequency of different voltage levels at one of PV PCCs.

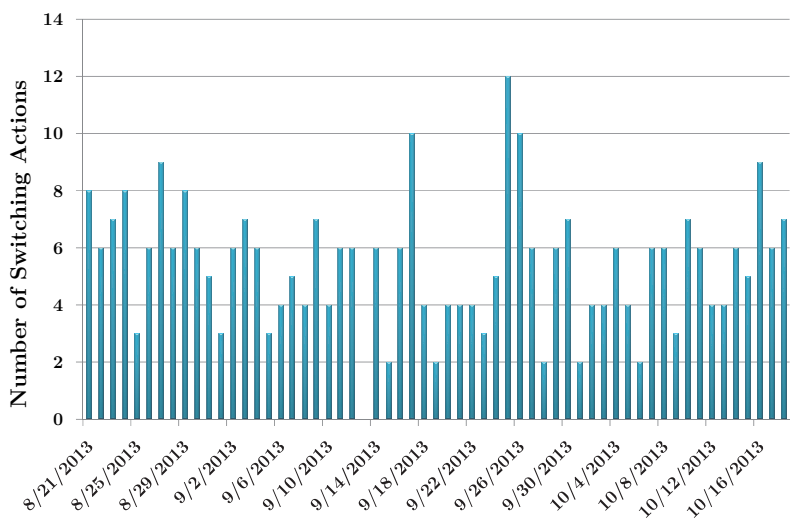

Fig. 13. The number of switching actions per day during the field tests.

consumption and decrease the power loss in the grid. However, to achieve a reliable voltage control solution, combination of DSM with other overvoltage prevention methods such as utilization of active transformers is necessary.

\section{CONCLUSION}

Efficient management of active LV grids with a high share of PV was investigated in this paper. A voltage droop control method for autonomous control of active MV/LV transformers was proposed. Simulations confirmed that by efficient control of active transformers, the limitation of installing new PV systems is no longer the overvoltage in the grid but the ratings of the grid components. In addition, the field test results associated with an active LV grid in Felsberg, Germany confirmed that, compared to the application of the fixed voltage approach, the proposed voltage droop control method increased the PV hosting capacity more, without reducing the lifespan of the transformer. It was also concluded that although the reactive power absorption by PV inverters can increase the PV hosting capacity, the increase is not considerable when the active transformer is utilized. In the future work, the coordination between active MV/LV transformers and HV/MV transformer will be considered for the efficient control of both MV and LV grids.

\section{REFERENCES}

[1] "Snapshot of Global PV Market", International Energy Agency (IEA) Photovoltaic Power Systems Program (PVPS), T1-24, 2015. 


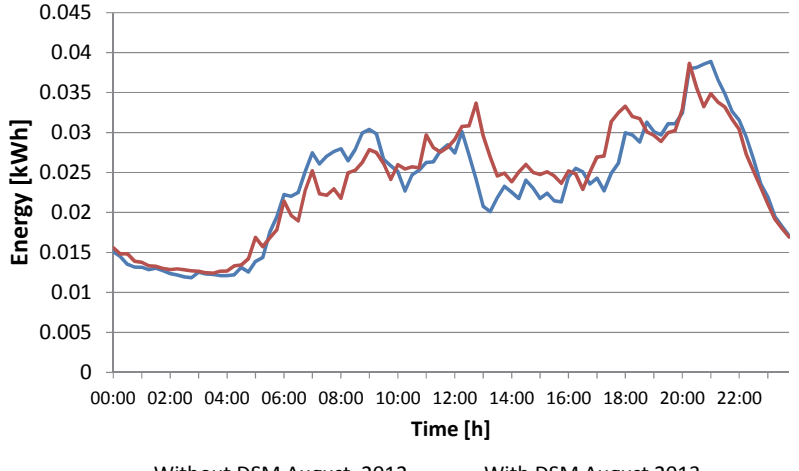

—Without DSM August 2012 —With DSM August 2013

Fig. 14. Average weekdays load profiles of 35 customers in August 2012 and 2013

[2] G. Masson, S. Orlandi, and M. Rekinger, "Global Market Outlook for PV 2014-2018," EPIA, 2014.

[3] S. Hashemi, J. Ostergaard, and G. Yang, "A Scenario-Based Approach for Energy Storage Capacity Determination in LV Grids With High PV Penetration," IEEE Trans. Smart Grid, vol. 5, pp. 1514-1522, May 2014.

[4] R. Tonkoski, D. Turcotte, and T. H. M. El-Fouly, "Impact of High PV Penetration on Voltage Profiles in Residential Neighborhoods," IEEE Trans. Sustain. Energy, vol. 3, pp. 518-527, Jul. 2012.

[5] T. Stetz, F. Marten, and M. Braun, "Improved Low Voltage GridIntegration of Photovoltaic Systems in Germany," IEEE Trans. Sustain. Energy, vol. 4, no. 2, pp. 534-542, Apr. 2013.

[6] M. Vogt, W. Heckmann, J. Hubert, T. Degner, and L. Bax, "Local use of PV surplus - load control and thermal storage in a LV grid cell", 7th International Conference on PV-Hybrids and Mini-Grids, Bad Hersfeld, Germany, 2014.

[7] C. Chen and S. Duan, "Optimal Integration of Plug-In Hybrid Electric Vehicles in Microgrids," IEEE Trans. Ind. Informatics, vol. 10, no. 3, pp. 1917-1926, Aug. 2014.

[8] S. Hashemi, W. Heckmann, D. Geibel, T. Degner, and J. Østergaard, "Application of MV/LV Transformers with OLTC for Increasing the PV Hosting Capacity of LV Grids," in 31th European Photovoltaic Solar Energy Conference and Exhibition, Hamburg, Germany, 2015.

[9] S. Eilenberger, D. Grob, K. Rudion, S. Tenbohlen, and I. Berber, "Modern voltage regulation methods for network planning and operation in low voltage grids," in 2015 IEEE Eindhoven PowerTech, 2015, pp. 16.

[10] T. Stetz, K. Diwold, M. Kraiczy, D. Geibel, S. Schmidt, and M. Braun, "Techno-economic assessment of voltage control strategies in low voltage grids," IEEE Trans. Smart Grid, vol. 5, no. 4, pp. 2125-2132, 2014.

[11] J. Hu, M. Marinelli, M. Coppo, A. Zecchino, and H. W. Bindner, "Coordinated voltage control of a decoupled three-phase on-load tap changer transformer and photovoltaic inverters for managing unbalanced networks," Electr. Power Syst. Res., vol. 131, pp. 264-274, Feb. 2016.

[12] J. Büchner, J. Katzfey, O. Flörcken, A. Moser, H. Schuster, S. Dierkes, T. van Leeuwen, L. Verheggen, M. Uslar, and M. van Amelsvoort, "Moderne Verteilernetze für Deutschland," federal ministry for economic affairs and energy of Germany, 2014.

[13] X. Liu, A. Aichhorn, L. Liu, and H. Li, "Coordinated Control of Distributed Energy Storage System With Tap Changer Transformers for Voltage Rise Mitigation Under High Photovoltaic Penetration," IEEE Trans. Smart Grid, vol. 3, no. 2, pp. 897-906, Jun. 2012.

[14] A. Einfalt, F. Zeilinger, R. Schwalbe, B. Bletterie, and S. Kadam, "Controlling active low voltage distribution grids with minimum efforts on costs and engineering," IECON Proc. (Industrial Electron. Conf., pp. 7456-7461, 2013.

[15] S. Paudyal, C. a. Canizares, and K. Bhattacharya, "Optimal Operation of Distribution Feeders in Smart Grids," IEEE Trans. Ind. Electron., vol. 58, no. 10, pp. 4495-4503, 2011.

[16] D. Pudjianto, P. Djapic, M. Aunedi, C. K. Gan, G. Strbac, S. Huang, and D. Infield, "Smart control for minimizing distribution network reinforcement cost due to electrification," Energy Policy, vol. 52, pp. 76-84, Jan. 2013.
[17] R. A. Mastromauro, M. Liserre, and A. Dell'Aquila, "Control Issues in Single Stage Photovoltaic Systems: MPPT, Current and Voltage Control," IEEE Trans. Ind. Informatics, vol. 8, no. 2, pp. 241-254, May 2012.

[18] R. Tonkoski, D. Turcotte, and T. H. M. El-Fouly, "Impact of High PV Penetration on Voltage Profiles in Residential Neighborhoods," IEEE Trans. Sustain. Energy, vol. 3, no. 3, pp. 518-527, Jul. 2012.

[19] F. Marra, G. Yang, C. Traeholt, J. Ostergaard, and E. Larsen, "A Decentralized Storage Strategy for Residential Feeders With Photovoltaics," IEEE Trans. Smart Grid, vol. 5, pp. 974-981, 2014.

[20] N. Etherden, V. Vyatkin, and M. H. J. Bollen, "Virtual Power Plant for Grid Services Using IEC 61850," IEEE Trans. Ind. Informatics, vol. 12, no. 1, pp. 437-447, Feb. 2016.

[21] M. N. Kabir, Y. Mishra, G. Ledwich, S. Member, Z. Y. Dong, and K. P Wong, "Coordinated Control of Grid-Connected Photovoltaic Reactive Power and Battery Energy Storage Systems to Improve the Voltage Profile of a Residential Distribution Feeder," IEEE Trans. Ind. Informatics, vol. 10, no. 2, pp. 967-977, May 2014.

[22] "Voltage Characteristics of Electricity Supplied by Public Distribution System”, Std. EN 50160, CENELEC, European Norm, 2010.

[23] G. Arnold, T. Degner, F. Gafaro, D. Geibel, W. Heckmann, T. Reimann, and B. Idlbi, "Aktives, intelligentes Niederspannungsnetz", 2014.

[24] Q. Chen, D. Kaleshi, Z. Fan, and S. Armour, "Impact of Smart Metering Data Aggregation on Distribution System State Estimation," IEEE Trans. Ind. Informatics, pp. 1-1, 2016.

[25] F. A. S. Borges, R. A. S. Fernandes, I. N. Silva, and C. B. S. Silva, "Feature Extraction and Power Quality Disturbances Classification Using Smart Meters Signals," IEEE Trans. Ind. Informatics, vol. 12, no. 2, pp. 824-833, Apr. 2016.

Seyedmostafa Hashemi (S’09) received the B.Sc. and M.Sc. degree (Hons.) in Electrical Engineering from Isfahan University of Technology, Isfahan, Iran, in 2006 and 2009, respectively. Currently, he is working toward the Ph.D. degree at the Center for Electric Power and Energy, Department of Electrical Engineering, Technical University of Denmark, Lyngby, Denmark. His research interests include Smartgrid, energy storage, and uncertainty modeling.

Jacob Østergaard (M'95, SM'09) is Professor and head of the Center for Electric Power and Energy (CEE) at the Department of Electrical Engineering, Technical University of Denmark, Lyngby, Denmark. He is also the head of experimental platform for power and energy, PowerLabDK. His research focus is on the development of the future intelligent power system with increased distributed and environmental friendly generation.

Thomas Degner is Head of Department Network Technology and Integration at Fraunhofer IWES, Kassel, Germany. He received his Diploma in Physics and his $\mathrm{PhD}$ in 1989 and 1996 respectively from University of Oldenburg. In 1998 he joined Fraunhofer IWES ("ISET" at that time). His particular interests include microgrids, interconnection requirements and testing procedures for distributed generators, as well as power system stability and control for island and interconnected power systems with a large share of renewable generation.

Ron Brandl finished as graduated engineer (Dipl.-Ing.) in Electrical Engineering in 2010 at the University Stuttgart, Germany. Since 2011 he is working as a researcher at the Fraunhofer Institute for Wind Energy and Energy System Technology, where he focuses on power system integration of renewable energy resources. His expertise includes power system stability, power hardware-in-the-loop technology, modelling and testing.

Wolfram Heckmann graduated in electrical engineering (Dipl.-Ing.) from the Technical University of Karlsruhe, Germany, in 1997. He is working with Fraunhofer IWES in Kassel, Germany, since 2007 in the area of grid integration of renewables and international laboratory networks. He is the German participant in the "Smart grid International Research Facilities Network - SIRFN" of the International Energy Agency, Implementing Agreement ISGAN. His research is focusing on secure grid operation regarding renewables, micro-grids, and network protection. 